Provided for non-commercial research and education use. Not for reproduction, distribution or commercial use.

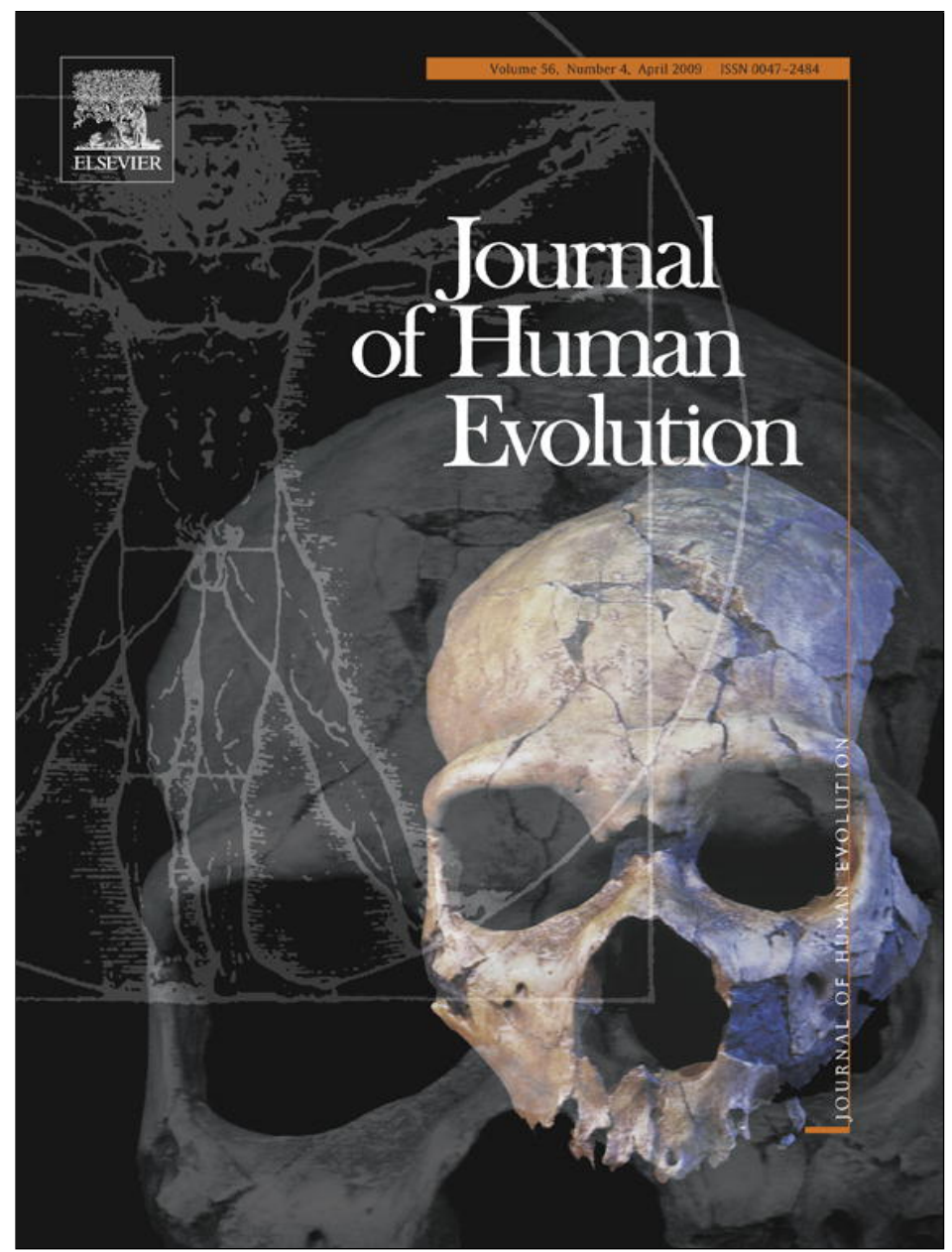

This article appeared in a journal published by Elsevier. The attached copy is furnished to the author for internal non-commercial research and education use, including for instruction at the authors institution and sharing with colleagues.

Other uses, including reproduction and distribution, or selling or licensing copies, or posting to personal, institutional or third party websites are prohibited.

In most cases authors are permitted to post their version of the article (e.g. in Word or Tex form) to their personal website or institutional repository. Authors requiring further information regarding Elsevier's archiving and manuscript policies are encouraged to visit:

http://www.elsevier.com/copyright 


\title{
Optimal running speed and the evolution of hominin hunting strategies
}

\author{
Karen L. Steudel-Numbers ${ }^{\mathrm{a}, *}$, Cara M. Wall-Scheffler ${ }^{\mathrm{b}}$ \\ a Department of Zoology, University of Wisconsin, Madison, WI 53706, USA \\ ${ }^{\mathrm{b}}$ Department of Biology, Seattle Pacific University, Seattle, WA 98195, USA
}

\section{A R T I C L E I N F O}

\section{Article history:}

Received 25 March 2008

Accepted 21 November 2008

\section{Keywords:}

Locomotion

Walking

\begin{abstract}
A B S T R A C T
Recent discussion of the selective pressures leading to the evolution of modern human postcranial morphology, seen as early as Homo erectus, has focused on the relative importance of walking versus running. Specifically, these conversations have centered on which gait may have been used by early Homo to acquire prey. An element of the debate is the widespread belief that quadrupeds are constrained to run at optimally efficient speeds within each gait, whereas humans are equally efficient at all running speeds. The belief in the lack of optimal running speeds in humans is based, however, on a number of early studies with experimental designs inadequate for the purpose of evaluating optimality. Here we measured the energetic cost of human running $(n=9)$ at six different speeds for five minutes at each speed, with careful replicates and controls. We then compared the fit of linear versus curvilinear models to the data within each subject. We found that individual humans do, in fact, have speeds at which running is significantly less costly than at other speeds (i.e., an optimal running speed). In addition, we demonstrate that the use of persistence hunting methods to gain access to prey at any running speed, even the optimum, would be extremely costly energetically, more so than a persistence hunt at optimal walking speed. We argue that neither extinct nor extant hominin populations are as flexible in the chosen speeds of persistence hunting pursuits as other researchers have suggested. Variations in the efficiency of human locomotion appear to be similar to those of terrestrial quadrupeds.
\end{abstract}

(c) 2008 Elsevier Ltd. All rights reserved.

\section{Introduction}

For approximately the first three million years of human evolution, our ancestors were characterized by a postcranial anatomy that was clearly reflective of bipedal gait but with elements that may have compromised their effectiveness in terrestrial locomotion (Ward, 2002). Most investigators (see citations in Wood and Collard, 1999) have interpreted the postcranial anatomy in reconstructed specimens from African populations of Homo erectus (relatively long legs, shorter arms, wide shoulders, narrow waist) as indicating substantial efficiency in terrestrial bipedality. Thus this adaptation is thought to have occurred by 1.8 million years ago. The application of the present data to hominin hunting strategies adopts that interpretation. This interpretation is challenged, however, by a newly described $H$. erectus pelvis (Simpson et al., 2008: 1091), which led those workers to conclude that the "basic features of $H$. erectus body shape remain poorly understood." Most investigators that have distinguished between gaits (walking and running) have traditionally assumed that these

\footnotetext{
* Corresponding author.

E-mail address: ksteudel@wisc.edu (K.L. Steudel-Numbers).
}

adaptations were adopted through selection acting on hominins engaged in walking (Jungers and Stern, 1983; Lovejoy, 1988; Crompton et al., 1998; Foley and Elton, 1998; Kramer, 1999; Kramer and Eck, 2000). Other workers (Carrier, 1984; Bramble and Lieberman, 2004), however, have suggested that selection for many modern postcranial characteristics seen in early Homo may have resulted from running. One of the assumptions involved in some of the arguments for this latter hypothesis has been that human running (unlike that of quadrupeds) is not characterized by a speed at which running is optimally efficient (Carrier, 1984; Bramble and Lieberman, 2004). The cost of human walking increases curvilinearly with speed, resulting in a series of speeds at which the cost to walk a given distance is optimal (Cotes and Meade, 1960; Margaria et al., 1963; Menier and Pugh, 1968; Carrier, 1984; McArdle et al., 2001; Bramble and Lieberman, 2004). In contrast, there is an almost universally accepted belief that the cost for a human to run increases linearly with speed (per unit time), so that the cost to run a given distance is speed invariant (Margaria et al., 1963; Menier and Pugh, 1968; Carrier, 1984; McArdle et al., 2001; Bramble and Lieberman, 2004), though there have been indications that this might not be the case (Boje, 1944; Walt and Wyndham, 1973). Thus, researchers have suggested that the amount of energy used to run a given distance is (nearly) the same, whether run quickly or slowly 
(Margaria et al., 1963; Kram and Taylor, 1990); thus proponents of 'running' hypotheses suggest the importance of a running gait for giving hominins flexibility in strategies during hunting (Carrier, 1984).

Hominin flexibility comes in contrast to the idea that quadrupeds have optimal speeds within gaits. This understanding stems from Hoyt and Taylor's (1981) elegant demonstration that within a single species (ponies, $n=3$ ), the cost of locomotion within gaits (walk, trot, gallop) increases curvilinearly with velocity, even when data only on freely chosen gaits were analyzed. This result, coupled with the observation in several species of a preference for selecting speeds in the middle of the range of speeds at which a given gait is used (Pennycuick, 1979), has led to the widespread belief that there are generally speeds within the gaits of quadrupeds that are less metabolically costly. In fact, data from all other quadrupedal species report a linear increase of cost with speed at all gaits (see Taylor et al. [1982] for a summary). Yet, because the experimental designs of most studies were not adequate to detect the fine difference between linearity and curvilinearity, the data on ponies have been generalized to all quadrupeds.

Carrier (1984) thus proposed that because humans do not have an optimal running speed, and any quadrupedal prey would be characterized by gait optima, human hunters would be free to pursue quadrupedal prey at running speeds suboptimal for the prey. This was a significant element in his argument that selection for endurance running may have been important in the evolution of Homo. Bramble and Lieberman (2004) echo this point in their recent overview, but give it less emphasis.

Many of the early works that were interpreted as suggesting speed invariance in human running were based on studies with small sample sizes (e.g., $n=2$; Margaria et al., 1963) or, like most studies of quadrupeds, experimental designs that would have made speed optimality difficult to detect (Boje, 1944; Hagan et al., 1980). More importantly, again like the earlier works reporting a linear increase in the cost of locomotion in quadrupeds (Taylor et al., 1970, 1982; Taylor, 1977), actual statistical comparison of the variance explained by the curvilinear versus linear models in human running was often omitted. The differences in the cost to run a given distance at different speeds are subtle in both humans and in quadrupeds. In addition, the majority of earlier work on human running looks at the cost per unit time (Boje, 1944; Margaria et al., 1963; Conley and Krahenbuhl, 1980; Hagan et al., 1980; Daniels and Daniels, 1992; Sherman, 1998), rather than the cost per unit distance. Among quadrupeds, it is the cost per unit distance in which the speed dependence of locomotor cost becomes apparent in both walking and running (Hoyt and Taylor, 1981). Given the importance of this question to discussions of possible hunting strategies among early hominins, it seems worthwhile to revisit the question of the linearity of cost of human running at increasing speeds, using a more carefully controlled experimental design.

\section{Methods}

The protocol was approved by the University of WisconsinMadison's Institutional Research Board, and all participants signed written informed consent. The protocol consisted of nine participants for whom we measured the cost to run at each of six different speeds on a motor driven treadmill for five minutes at each speed, while his or her metabolic rate was monitored using a SensorMedics VMax 29c system. This system provides a breath by breath analysis of oxygen consumed and carbon dioxide produced in units of $\mathrm{L} / \mathrm{min}$. These values were converted to kcal using Weir's (1949) standard calculation. We did not measure heart rate. Room temperature was consistent at approximately $21^{\circ} \mathrm{C}$. The six running speeds were chosen by each participant from a series of options. The options were 2.0, 2.5, 2.7, 3.1, 3.6, 4.0, 4.5, or $4.9 \mathrm{~ms}^{-1}$. Each participant chose two speeds s/he considered 'slow' two speeds s/he considered 'comfortable,' and two speeds which s/he considered 'fast,' but which they were still able to maintain aerobically $(\mathrm{RQ}<1.0)$. The six speeds were randomized each time a participant performed a trial. The randomization included two controls: neither of the two fastest speeds would be first, and the two fastest speeds would not be performed sequentially. These controls were used to prevent the fatigue and injury of our participants. Each participant walked at a self-selected speed between each five minute trial until his or her heart rate had returned to walking values. Subjects ran at all six speeds on at least five separate days within a three week period; each day of trials was separated by at least 48 hours from other trial days. Thus, subjects ran for a total of 30 minutes at a variety of speeds, many of which are very much in excess of those at which persistence hunting is practiced (Liebenberg, 2006). The metabolic values for each speed from at least four days were averaged to get the final cost of locomotion for each speed for each individual. From these data, we calculated the cost of transport (CoT [ $\mathrm{kcal} / \mathrm{km}]$ ) and cost of locomotion ( $\mathrm{CoL}[\mathrm{kcal} / \mathrm{min}]$; see further description below). Days in which a subject had a significant order effect, suggesting fatigue, were not included. We compared the fit of linear versus curvilinear models to the data within each subject, thus each subject acts as his/her own control. This is important because, as we show below, different subjects have different speed optima.

We measured each subject's height, mass, and lower-limb length. Lower-limb length was measured as in Steudel-Numbers and colleagues (Steudel-Numbers and Tilkens, 2004; SteudelNumbers et al., 2007). For each subject we compared the rate of increase in cost with speed, using both linear and curvilinear models created from linear and quadratic regressions. This was done for both the cost per unit time $(\mathrm{CoL})$ and for the cost per unit distance (CoT). The comparisons of cost per unit time are comparable to most previous reports on the cost of human running, but the cost per unit distance is a measure of energetic efficiency and is a more appropriate measure for understanding adaptation (Steudel, 2000; Steudel-Numbers, 2006). CoT measures the cost of a given task (travelling a given distance), and thus has a specific ecological meaning, rather than simply the cost to locomote at a particular speed for a particular time. $R^{2} s$ and $p$-values were calculated for each subject under a linear and a curvilinear model for both cost per unit time and cost per unit distance. Comparisons between the models were done using paired $t$-tests.

\section{Results}

Using metabolic data on multiple running speeds from nine human participants, we tested the fit of both linear and curvilinear models for both CoL and CoT. Figure 1 illustrates the data for the cost per unit distance of running at various speeds for each of our subjects, with best-fit lines for both models. Fitting a curvilinear model produces consistently and conspicuously higher correlations and lower $\mathrm{p}$-values than does fitting a linear model. The mean $\mathrm{R}^{2}$ for fitting a curvilinear model to the cost-speed data across all subjects is 0.94 , while the mean $R^{2}$ with a linear model is only 0.41 . The difference (using paired $t$-tests) between the two models is again highly significant at $\mathrm{p}=0.001$. As in previous studies, the linear model (CoL) showed a good fit with an average $\mathrm{R}^{2}$ of 0.984 (Fig. 2). Nonetheless, the curvilinear model fit the data even better: $\mathrm{R}^{2}=0.998$, a highly significant difference $(\mathrm{p}=0.001)$.

In addition to a model applicable to our whole sample, two other variables emerged from these data: the impact of size and perhaps sex. Our female subjects chose running speeds similar to and not significantly different from those of males $(\mathrm{p}=0.375)$. 

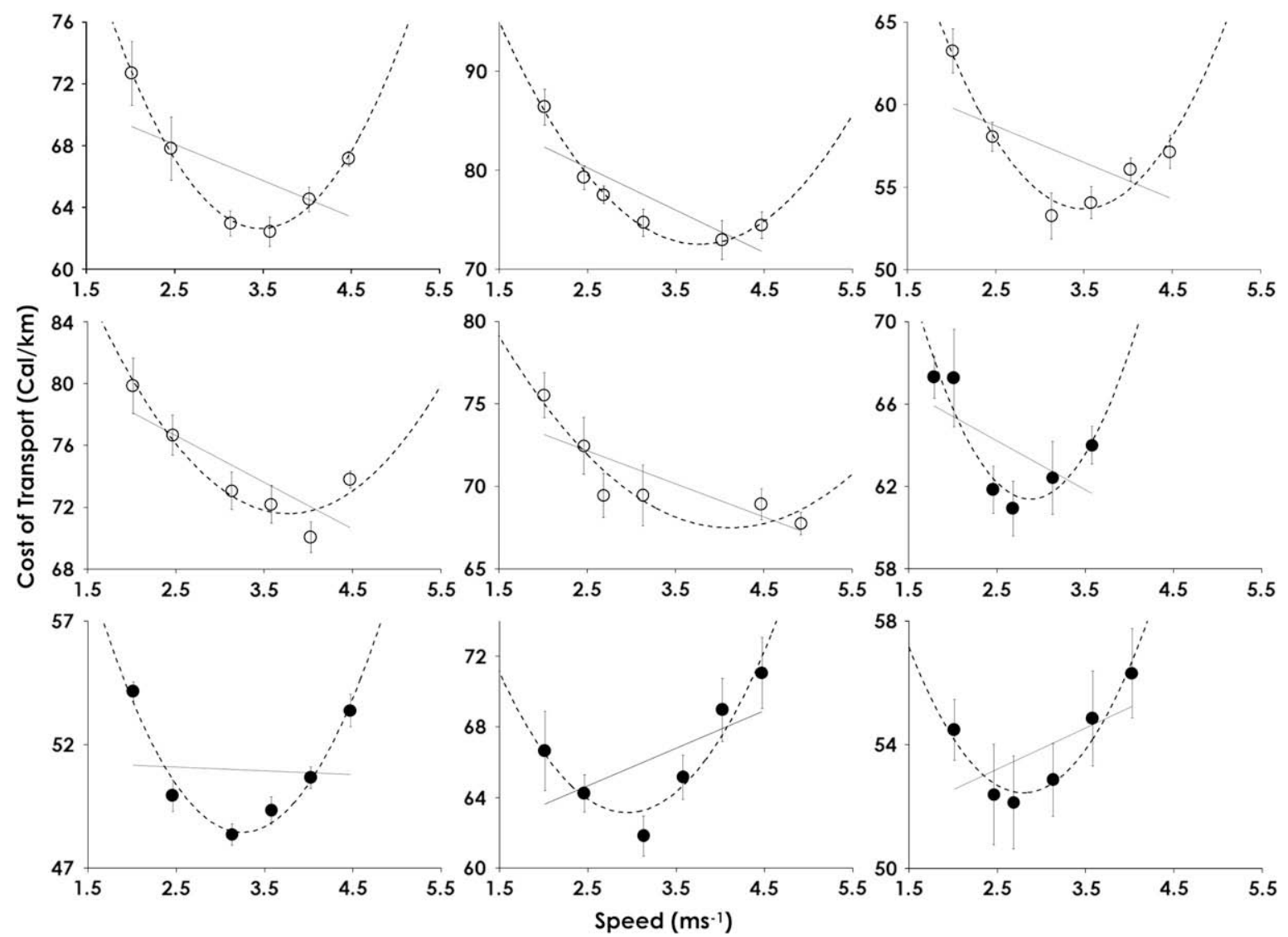

Figure 1. Each individual participant's CoT data (point) with both a linear and curvilinear line fit. Open circles are males; closed circles are females. Error bars are the standard error of mean values averaged over the trials at each speed.

Nonetheless, optimal running speeds averaged $2.9 \mathrm{~ms}^{-1}$ in females and $3.7 \mathrm{~ms}^{-1}$ in males. Because our males were on average taller $(179.6 \mathrm{~cm}$ versus $168.2 \mathrm{~cm})$, longer limbed $(87 \mathrm{~cm}$ versus $81 \mathrm{~cm})$, and heavier (72 kg versus $66.7 \mathrm{~kg}$ ) than our females, we suspect that this is a simple consequence of size, although we cannot rule out some other sex effect. Optimal running speed is significantly correlated with body mass $(\mathrm{R}=0.774, \mathrm{p}=0.024)$.

To evaluate the impact that the curvilinearity of the cost of running would have on the ability of early Homo to pursue prey using endurance running, we compared the cost to travel $27.8 \mathrm{~km}$ (the average distance of a persistence hunt reported by Liebenberg [2006]) while running at optimal running speeds, with running $27.8 \mathrm{~km}$ at least-optimal running speeds. On average, our males would spend $1798 \mathrm{kcal}$ in a hunt at optimal running speed. A hunt at the least efficient speed would add an extra $302 \mathrm{kcal}$. Our females would spend an average of $1552 \mathrm{kcal}$ on a hunt at optimal speed, adding $177 \mathrm{kcal}$ when running at the least optimal speed. Their hunt would of course also take longer (because of their slower optima), so would fall under constraints of time (day length) as well as energy.

\section{Discussion}

Why did these data demonstrate curvilinearity in the cost of human running when most investigators had been under the impression that it was linear? Probably the most important factor was the combination of the subtlety of difference between the linear and curvilinear fits of the CoL curves, and the fact that the CoL curve has been preferenced in biomechanics literature over and above the CoT curve. The fit of the linear model to the cost per unit time data in the present study, $\mathrm{R}^{2}=0.984$, is virtually identical to the fit of the same variable reported by Hoyt and Taylor (1981) for their data on ponies using freely chosen gaits $\left(R^{2}=0.98\right.$ or above). Detecting such a small difference requires a very careful experimental design. Until Hoyt and Taylor (1981) carried out their painstaking experiments, it was thought that the cost of quadrupedal running was linear (Taylor et al., 1970, 1982; Taylor, 1977) . Like the early work on quadrupeds, most of the early studies on humans had methodological problems as discussed in the Introduction. The present study is the first to attempt to address this issue for human running with an experimental design as carefully controlled as that of Hoyt and Taylor's (1981) in quadrupeds.

What implications does this have for the evolution of human running? Since there are few reports in the ethnographic literature of females engaging in endurance running, we use the estimates from our male subjects to estimate the implications of running at non-optimal running speeds for early Homo. The new pelvis from Gona (Simpson et al., 2008) underscores the unlikelihood of endurance running by female Homo. The earliest we see body mass and locomotor morphology similar to that of modern humans is among certain populations of $H$. erectus (Ruff and Walker, 1993; Ward, 2002; Bramble and Lieberman, 2004; Steudel-Numbers and Tilkens, 2004). Further, it is specifically African H. erectus that is proposed as the first hominin to engage in hunting involving substantial travel distances (Issac, 1984; Foley and Elton, 1998; Wrangham et al., 1999; Binford, 2001; O'Connell et al., 2002; Bramble and Lieberman, 2004; although see Simpson et al., 2008) or persistence hunting (Carrier, 1984; Bramble and Lieberman, 2004). We thus use estimates of daily energy expenditure (DEE) from the literature specifically for KNM-WT 15000 (Steudel-Numbers, 2006). 

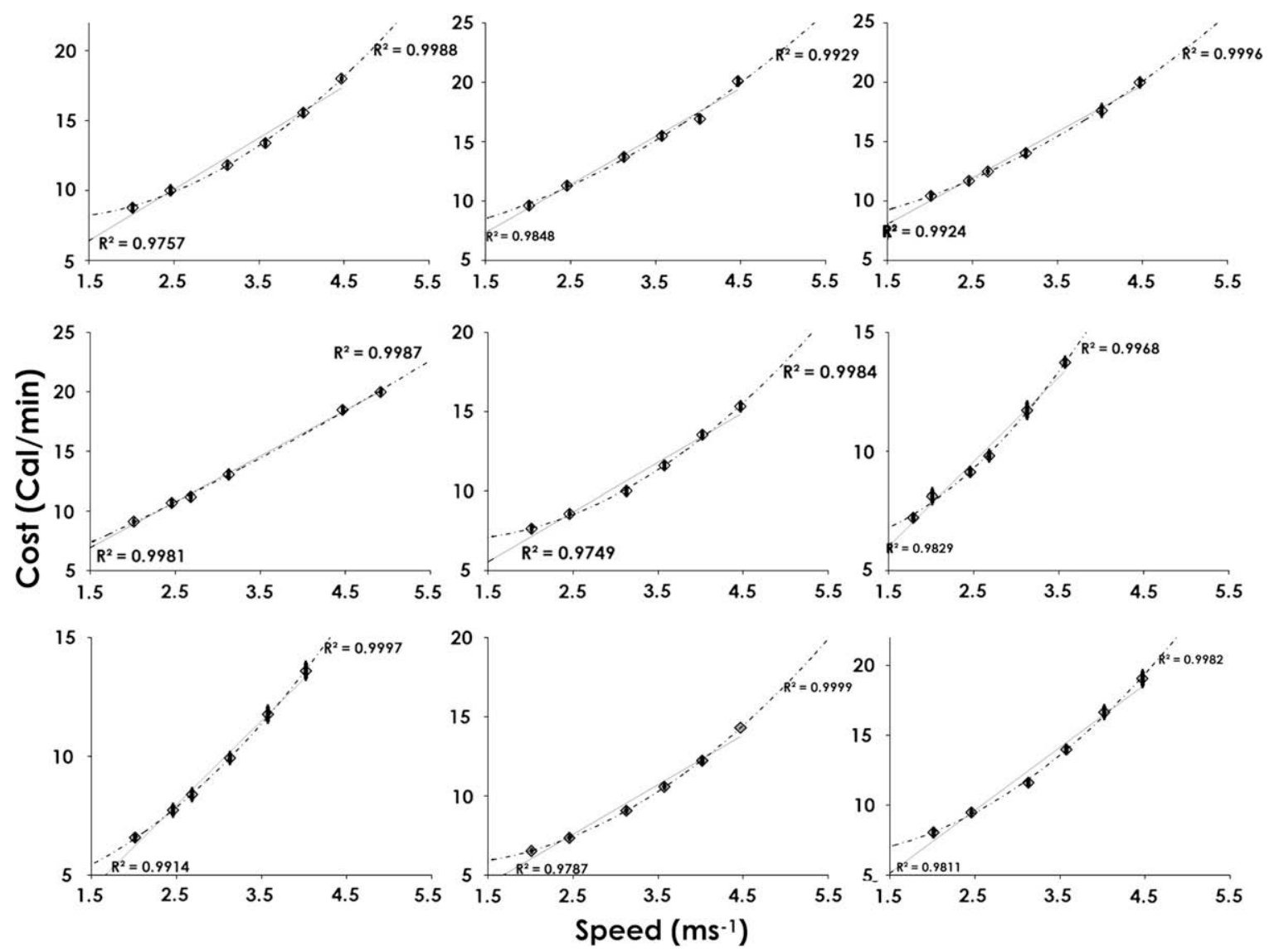

Figure 2. Each individual participant's CoL data (point) with both linear and curvilinear line fits. Open diamonds are males; closed diamonds are females. The $\mathrm{R}^{2}$ values on the bottom left are for the linear fit; the values on the top right are for the curvilinear fit. Error bars are the standard error of mean values averaged over the trials at each speed; they are small and thus, may be challenging to see.

That study built on previous work estimating DEE (Leonard and Robertson, 1997; Key and Ross, 1999) and added more accurate estimates of locomotor costs. Estimates of body mass for this specimen, $68 \mathrm{~kg}$ (Ruff and Walker, 1993), are similar to the average for the males in the present study, $71.5 \mathrm{~kg}$. How would engaging in a bout of persistence hunting involving the average distance reported for a hunt in modern persistence hunters (Liebenberg, 2006) at optimal versus suboptimal speed affect the daily energy budget of KNM-WT 15000? Average daily energy expenditure for KNM-WT 15000 is estimated at $2487 \mathrm{kcal}$ (Steudel-Numbers, 2006). As the average cost for our male subjects to engage in an average length bout of persistence hunting at optimal speed is $1798 \mathrm{kcal}$, a persistence hunt at optimal running speed would cost $72 \%$ of the total DEE expected for this individual. The increase of $302 \mathrm{kcal}$ occurring if the hunt transpired at suboptimal speed would be another $12 \%$ of the DEE for this individual. Thus, performing persistence hunting at suboptimal speed would utilize $84 \%$ of an $\mathrm{H}$. erectus individuals' DEE, implying that persistence hunting would have been an energetically costly activity. The impact of the costs of persistence hunting using walking and running at optimal and suboptimal speeds is shown graphically in Figure 3.

Would persistence hunting at walking speeds be a viable strategy? The average speed of all observed persistence hunts reported by Liebenberg (2006) was $1.72 \mathrm{~ms}^{-1}$, a speed at which walking is usually preferred (Thorstensson and Roberthson, 1987; Hreljac, 1995). The cost of a persistence hunt walking at $1.72 \mathrm{~ms}^{-1}$ would be $1583 \mathrm{kcal}$, based on averaged estimates from Cotes and Meade (1960) and Margaria et al. (1963). This would be $64 \%$ of
H. erectus DEE, a substantial reduction. If a persistence hunt could be carried out at or near optimal walking speed, the cost would drop further. We calculated the cost for an individual of the estimated mass and limb length of KNM-WT 15000 to travel the $27.8 \mathrm{~km}$ of a typical persistence hunt (Liebenberg, 2006), while walking at near-optimal speed based on the equation in SteudelNumbers and Tilkens (2004). This cost would be $1407 \mathrm{kcal}, 57 \%$ of DEE (compared to the $72 \%$ of DEE to travel the same distance at optimal running speed). Walking is thus considerably cheaper.

Whether optimal walking speeds could be used in a persistence hunt is, of course, another question. Given that tracking is often

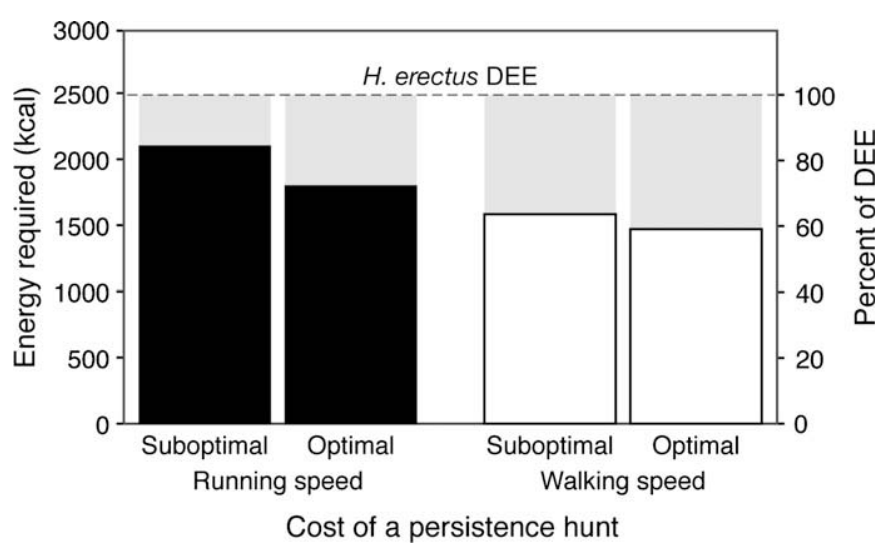

Figure 3. The cost of a persistence hunt using walking versus running at optimal and suboptimal speeds compared to the estimated total daily energy budget of $H$. erectus. 
required (Liebenberg, 2006) and that the average pace reported for the persistence hunts observed by Liebenberg (2006) was a speed at which humans can either walk briskly or run slowly, it seems likely some mixture of walking and running speeds would be used, mitigating the cost of a hunt carried out solely at running speeds. Unfortunately, for all of our male subjects and most of our female subjects, their slowest running speed was the least efficient (see Fig. 1). Thus, selecting a slow steady running pace for a persistence hunt would not be a good energetic choice.

While persistence hunting would have been energetically costly to the hunter or hunters, the potential pay off may have made it worthwhile. Lieberman et al. (2007) estimate the caloric value the meat of a $13 \mathrm{~kg}$ duiker as $15,600 \mathrm{kcal}$ and that of a $200 \mathrm{~kg}$ ungulate as $240,000 \mathrm{kcal}$. These large caloric benefits would certainly repay the investment. Further, a hunter delivering the coupe de grace to an exhausted animal would not face the injury risks of a hunter facing a healthy foe. On the other hand, the water balance of the hunter(s) must surely be a factor, particularly given the belief that hot conditions are important to the success of a persistence hunt (Liebenberg, 2006; Lieberman et al., 2007). Liebenberg (2006) reports that the hunters involved in the persistence hunts filmed for his television documentary were allowed to refill their two-liter plastic water bottles during the hunt. He did not specify how many refills were needed. If only one refill was required, this would be a total of $4 \mathrm{~kg}$ per hunter. It seems unlikely that early Homo would have had a source of resupply, thus these early hunters would have had to carry enough water to prevent serious heat stroke, which based on the modern simulation would have been at least $4 \mathrm{~kg}$. Given that the containers available to early Homo would presumably have been skins or gourds, the hunters would have been burdened. At the very least this would have increased their energetic cost, but it may have interfered with their ability to run smoothly as well.

Because modern humans do have an optimal running speed and it is likely extinct hominins did as well, there is an ideal speed at which hominins can most efficiently pursue prey animals. Carrier (1984) suggests that a good pursuit speed would be one "midway between the optimal speed of the trot and the optimal speed of the gallop." Since ethnographic reports might limit our understanding of extinct hominin strategies, we also want to consider possible strategies based on the prey available to and accessed by East African Homo erectus. In order to calculate the likely optimal pursuit speed for $H$. erectus, we used published equations for optimal trotting and optimal galloping speeds (Heglund and Taylor, 1988) of prey animals of the size observed in the $H$. erectus archaeological record. We then calculated the midpoint between the two optimal speeds as the optimal pursuit speed. Blumenschine and Pobiner (2007) suggest four prey size-categories for those ungulates which have butchery marks at East African Oldowan sites. The categories are $5-25 \mathrm{~kg}, 25-125 \mathrm{~kg}, 125-350 \mathrm{~kg}$, and above $350 \mathrm{~kg}$. Blumenschine and Pobiner (2007) do not suggest hominins were hunting animals from all of the size ranges, so we have chosen to consider mid-range values from the first three categories $(10 \mathrm{~kg}, 60 \mathrm{~kg}$, and $200 \mathrm{~kg}$ ) as reasonable brackets. For a $10 \mathrm{~kg}$ animal, the optimal pursuit speed should be $3.0 \mathrm{~ms}^{-1}$; for a $60 \mathrm{~kg}$ animal, optimal pursuit speed should be $4.2 \mathrm{~ms}^{-1}$; and for a $200 \mathrm{~kg}$ animal, $5.3 \mathrm{~ms}^{-1}$. Thus, the optimal running speed for a $H$. erectus individual of the size of KNM-WT 15000 of somewhere around $3.7 \mathrm{~ms}^{-1}$ (extrapolated from present data) would be most suitable for pursuing the medium sized prey, though again at $72 \%$ of the individual's total DEE. Interestingly, the optimal running speed estimated for an individual in the middle of the size range suggested by Lordkipanidze et al. (2007) for the Dmanisi H. erectus is $1.97 \mathrm{~ms}^{-1}$, below the optimal pursuit speed for any of the prey species known from East Africa. The cooler climate characteristic of this site
Table 1

A summary of the hypothesized role of each gait on hominin evolution.

\begin{tabular}{ll}
\hline Locomotion strategy & Impact on early Homo \\
\hline Walking & $\begin{array}{l}\text { Movement between patchy resources can } \\
\text { occur at low energetic cost }\end{array}$ \\
No optimal running speed & $\begin{array}{l}\text { Hominin hunters are free to pursue quadrupedal } \\
\text { prey at running speeds suboptimal for the prey } \\
\text { (not supported by current evidence) } \\
\text { Optimal running speed }\end{array}$ \\
$\begin{array}{l}\text { Hominin hunters incur additional increased costs } \\
\text { of around 12\% of their total DEE by running at their } \\
\text { sub-optimal speed }\end{array}$ \\
\hline
\end{tabular}

(Sarmiento et al., 2007) may also have made persistence hunting a less likely adaptive strategy for these hominids, given that most advocates of the relevance of persistence hunting as an adaptive strategy for early Homo argue that it would be most effective under very hot environmental conditions (Liebenberg, 2006; Lieberman et al., 2007).

Thus, in showing that an optimal speed of human running exists, we note that early Homo may not have been as flexible in the chosen speeds of running pursuits as other researchers have suggested (see Table 1 for summary). In addition, a persistence hunt, even at optimal running speed, would have been extremely energetically costly, considerably more so than a persistence hunt at optimal walking speed.

\section{Acknowledgments}

We would like to thank Prof. R.A. Foley, T. Weaver, M.J. Myers, and the anonymous reviewers for comments that have greatly improved the manuscript. Bill Feeny prepared Figure 3. To our participants, we are grateful for their donation of time and energy.

\section{References}

Binford, L.R., 2001. Constructing Frames of Reference: An Analytical Method for Archaeological Theory Building using Hunter-Gatherer and Environmental Data Sets. University of California Press, Berkeley.

Blumenschine, R.J., Pobiner, B.L. 2007. Zooarchaeology and the ecology of Oldowan hominin carnivory. In: Ungar, P.S. (Ed.), Evolution of the Human Diet: The Known, the Unknown and the Unknowable. Oxford University Press, Oxford, pp. 167-190.

Boje, O., 1944. Energy production, pulmonary ventilation, and length of steps in well-trained runners working on a treadmill. Acta Physiol. Scand. 7, 362-374.

Bramble, D.M., Lieberman, D.E., 2004. Endurance running and the evolution of Homo. Nature 432, 345-352.

Carrier, D.R., 1984. The energetic paradox of human running and hominid evolution. Curr. Anthropol. 25, 483-495.

Conley, D.L., Krahenbuhl, G.S., 1980. Running economy and distance running performance of highly trained athletes. Med. Sci. Sports Exerc. 12, 357-360.

Cotes, J.E., Meade, F., 1960. The energy expenditure and mechanical energy demand in walking. Ergonomics 3, 97-120.

Crompton, R.H., Yu, L., Wang, W., Gunther, M., Savage, R., 1998. The mechanical effectiveness of erect and "bent-hip, bent-knee" bipedal walking in Australopithecus afarensis. J. Hum. Evol. 35, 55-74.

Daniels, J., Daniels, N., 1992. Running economy of elite male and elite female runners. Med. Sci. Sports Exerc. 24, 483-489.

Foley, R.A., Elton, S., 1998. Time and energy: The ecological context for the evolution of bipedalism. In: Strasser, E., Fleagle, J., Rosenberger, A., McHenry, H. (Eds.), Primate Locomotion: Recent Advances. Plenum Press, New York, pp. 419-433.

Hagan, R.D., Strathman, T., Strathman, L., Gettman, L.R., 1980. Oxygen uptake and energy expenditure during horizontal treadmill running. J. Appl. Physiol. 49, 571-575.

Heglund, N.C., Taylor, C.R., 1988. Speed, stride frequency and energy cost per stride: how do they change with body size and gait? J. Exp. Biol. 138, 301-318.

Hoyt, D.F., Taylor, C.R., 1981. Gait and the energetics of locomotion in horses. Nature 292, 239-240.

Hreljac, A., 1995. Effects of physical characteristics on the gait transition speed during human locomotion. Hum. Mov. Sci. 14, 205-216.

Issac, G., 1984. The archaeology of human origins: studies of the lower Pleistocene in East Africa, 1971-1981. Adv. World Archaeol. 3, 1-87.

Jungers, W., Stern Jr., J., 1983. Body proportions, skeletal allometry, and locomotion in the Hadar hominids: a reply to Wolpoff. J. Hum. Evol. 12, 673-684.

Key, C., Ross, C., 1999. Sex differences in energy expenditure in non-human primates. Proc. R. Soc. Lond. B. Biol. Sci. 266, 2479-2485. 
Kram, R., Taylor, C.R., 1990. Energetics of running: a new perspective. Nature 346, 265-267.

Kramer, P., 1999. Modelling the locomotor energetics of extinct hominids. J. Exp. Biol. 202, 2807-2818.

Kramer, P., Eck, G.G., 2000. Locomotor energetics and lower limb length in hominid bipedality. J. Hum. Evol. 38, 651-666.

Leonard, W.R., Robertson, M.L., 1997. Comparative primate energetics and hominid evolution. Am. J. Phys. Anthropol. 102, 265-282.

Liebenberg, L., 2006. Persistence hunting by modern hunter-gatherers. Curr. Anthropol. 47, 1017-1025.

Lieberman, D.E., Bramble, D.M., Raichlen, D.A., Shea, J.J., 2007. The evolution of endurance running and the tyranny of ethnography:a reply to Pickering and Bunn (2007). J. Hum. Evol. 53, 439-442.

Lordkipanidze, D., Jashashvili, T., Vekua, A., Ponce de Leon, M., Zollikofer, C., Rightmire, G.P., Pontzer, H., Ferring, R., Oms, O., Tappen, M., Bukhsianidze, M. Agusti, J., Kahlke, R., Kiladze, G., Martinez-Navarro, B., Mouskhelishvili, A. Nioradze, M., Rook, L., 2007. Postcranial evidence from early Homo from Dmanisi, Georgia. Nature 449, 305-310.

Lovejoy, C.O., 1988. Evolution of human walking. Sci. Am. 256, 118-125.

Margaria, R., Cerretelli, P., Aghemo, P., Sassi, G., 1963. Energy cost of running. J. Appl. Physiol. 18, 367-370.

McArdle, W.D., Katch, F.I., Katch, V.L., 2001. Exercise Physiology: Energy, Nutrition, and Human Performance, fifth ed. Lippincott, Williams and Wilkens, New York

Menier, D.R., Pugh, L.G.C.E., 1968. The relation of oxygen intake and velocity of walking and running in competition walkers. J. Physiol. (Lond) 197, 717-721.

O'Connell, J., Hawkes, K., Lupo, K., Blurton-Jones, N., 2002. Male strategies and PlioPleistocene archaeology. J. Hum. Evol. 43, 831-872.

Pennycuick, C.J., 1979. Energy costs of locomotionn and the concept of "foraging radius. In: Sinclair, A.R.E., Norton-Griffiths, M. (Eds.), Serengeti: Dynamics of an Ecosystem. University of Chicago Press, Chicago, pp. 164-184

Ruff, C.B., Walker, A., 1993. Body size and body shape. In: Walker, A., Leakey, R. (Eds.), The Nariokotome Homo erectus Skeleton. Harvard University Press, Cambridge.

Sarmiento, E.G., Sawyer, J., Milner, R., Deak, V., Tattersall, I., Johansen, D., Leakey, M., 2007. The Last Human: A Guide to Twenty-Two Species of Extinct Humans. Yale University Press, New Haven.
Sherman, N.W., 1998. Development of a generalized model to estimate the energy cost of walking and running for healthy adults. J. Strength Cond. Res. 12, 33-36.

Simpson, S.W., Quade, J., Levin, N.E., Butler, R., Dupont-Nivet, G., Everett, M. Semaw, S., 2008. A female Homo erectus pelvis from Gona, Ethiopia. Science 322, 1089-1092.

Steudel, K., 2000. The physiology and energetics of movement: Effects on individuals and groups. In: Boinski, S., Garber, P. (Eds.), On the Move: How and Why Animals Travel in Groups. University of Chicago Press, Chicago, pp. 9-23.

Steudel-Numbers, K., 2006. Energetics in Homo erectus and other early hominins: the consequences of increased lower limb length. J. Hum. Evol. 51, 445-453.

Steudel-Numbers, K., Tilkens, M.J., 2004. The effect of lower limb length on the energetic cost of locomotion: implications for fossil hominins. J. Hum. Evol 47, 95-109.

Steudel-Numbers, K., Weaver, T.D., Wall-Scheffler, C.M., 2007. The evolution of human running: effects of changes in lower limb length on locomotor economy. J. Hum. Evol. 53, 191-196.

Taylor, C.R., 1977. The energetics of terrestrial locomotion and body size in vertebrates. In: Pedley, T.J. (Ed.), Scale Effects in Animal Locomotion. Academic Press, New York, pp. 127-141.

Taylor, C.R., Heglund, N.C., Maloiy, G.M.O., 1982. Energetics and mechanics of terrestrial locomotion: 1 . Metabolic energy consumption as a function of speed and body size in birds and mammals. J. Exp. Biol. 97, 1-21.

Taylor, C.R., Schmidt-Nielsen, K., Raab, J.L., 1970. Scaling the energetic cost of running to body size in mammals. Am. J. Physiol. 219, 1104-1107.

Thorstensson, A., Roberthson, H., 1987. Adaptations to changing speed in human locomotion: speed of transition between walking and running. Acta Physiol. Scand. 131, 211-214.

Walt, W.H.V.D., Wyndham, C.H., 1973. An equation for prediction of energy expenditure of walking and running. J. Appl. Physiol. 34, 559-563.

Ward, C., 2002. Interpreting the posture and locomotion of Australopithecus afar ensis: where do we stand? Yearb. Phys. Anthropol. 45, 185-215.

Weir, J., 1949. New methods for calculating metabolic rate with special reference to protein metabolism. J. Physiol. (Lond.) 109, 1-9.

Wood, B., Collard, M., 1999. The human genus. Science 284, 65-71.

Wrangham, R.W., Jones, J.H., Laden, G., Pilbeam, D., Conklin-Brittain, N., 1999. The raw and the stolen: cooking and the ecology of human origins. Curr. Anthropol. $40,567-594$. 